\title{
The Health Care System as a New Competitive Factor in the Light of the Convergence Programme
}

\author{
DR CSABA LENTNER
}

\author{
Department of Accounting and Finance, Sub-Department of Finance, \\ University of West Hungary, Sopron, Hungary
}

\begin{abstract}
The new (old) government's manifesto and the convergence programme have given a new impulse to the transformation of the health care system in Hungary. The provision of health care to the population crucially rests upon the pillars of ambulatory and inpatient care. Thus the question of how much in funds is being made available by the government in order to keep the system up and running is of significant relevance. The principles and policies governing the allocation of those funds merit further investigation as well. This paper argues that the health care system should be regarded as a new factor in economic competitiveness. It is easy to see that the future functioning of the health care sector is contingent upon the path followed by public finances, which in turn are closely mirroring the key aspects of the new convergence programme. The study demonstrates with empirical methods that the health care and the social security systems, already crisis-ridden, are very likely to face even more serious problems if the budget deficits persist. The planned rationalisation measures in the health care sector may hamper efforts to reintegrate socially marginalised individuals and the long-term unemployed into the labour market. Due to the funding problems of the health care system the objective of maintaining and improving the optimal health status of the economically active population, allowing people to stay in good health while working, is also at risk. It is a straightforward conclusion then that the health care system, as a new competitive factor, is in need of investment and an overhaul in order to become more efficient and to be able to tackle the challenges lying ahead. It is reasonable to assume that the tasks facing the health care system will multiply in the years to come. This prospect calls not for a curtailment of but an increase in funding, as the health care system, being a new competitive factor, is creating value by maintaining and enhancing the health status of the population.
\end{abstract}

Keywords: health care finance, new competitive factor, convergence programme, social security system

\section{Abbreviations}

$\mathrm{EÜM}=$ Department of Health; GDP = Gross Domestic Product; SAP = Systems, Applications and Products in Data Processing; IBM = International Business Machines; GE = General Electric; EDS = Electronic Data Systems; EU = European Union; MNB = Central Bank of Hungary; ERM II = European Exchange Rate Mechanism II.

Corresponding address: Dr. Csaba lentner, Erzsébet u. 9., H-9400 Sopron, Hungary.

E-mail: drlentner@ktk.nyme.hu

DOI: 10.1556/HMJ.1.2007.1.12 
The global competitiveness of a country depends on many factors, which in turn may vary as a function of time. Having mastered the transition to a market economy and accession to the European Union Hungary is more than ever exposed to the forces of competition. A stable fiscal environment and a healthy and highly qualified workforce are among the most sought-after features of any economy in such a competitive setup. Hungary has fallen behind in all of the aforementioned areas. The budget and the balance of payments are running deficits, whereas the overall effectiveness, as well as the cost-efficiency of the higher education sector is deteriorating. Universities, knowledge and research centres and the health care system are - due to their weak efficiency and persistent funding problems - less and less capable of reproducing the stock of human capital, let alone improving and increasing it. In the light of the above issues one might ask himself, how the new government's manifesto will affect the competitive position of the Hungarian economy in general and the efficiency of the health care sector in particular.

\section{The Fiscal Environment as a New Competitive Factor}

The future prospects of the Hungarian health care system, a classic example of publicly financed and publicly administered services, will be considerably influenced by the situation surrounding public finances, the general state of the economy as well as its endowment with funds. The health care sector is financed directly by central government and social security funds, with the latter constituting two of the four subsystems (separate accounts) of which the budget is made up. Upon outlining future health policy directions we ought to account for the financial processes and capital flows taking place at a macro level in Hungary - now seamlessly integrated into the European economy - as they are key determinants in the transfer of funds towards the health care sector.

The fact that the Hungarian economy has been successful at mastering the transition from a planned to a market economy in the past two decades or so, may, in principle, provide a solid and auspicious foundation for the future development of the health care sector.

With multinational companies establishing their local operations the manufacturing sector of the economy experienced a wave of modernisation, boosting private sector growth in general. The state of public finances, however, is rather dire. It is best described by the twin-deficit and growing public debt on the one hand and by periodically recurring curtailments of public expenditure on social schemes and the education sector on the other. The fact that the Hungarian economy is a developed, or more precisely a successfully emerging one, was demonstrated by the accession of the country to the European Union, which was preceded by a lengthy integration process. The accession of the country to the EU does not mean, however, that the process of integration is finalised. Notwithstanding the promising trend in the inflation rate and the commanding growth rate of the economy up until mid-2006 the budget and the balance of payments deficits have reached critical levels. Upon examining the fiscal policies implemented during the transition to a market economy it becomes obvious that the drafting and preparation phase paving the way for the reforms is too extended, while the measures themselves are of short-term effect.

2005 was a seminal year for Hungary: never before in the post-communist era was as much foreign capital invested in net terms ${ }^{1}$ in the economy as in that year. As a matter of fact foreign direct investment exceeded the year 2005 figure only in 1995, at the time of mass privatisation. As a consequence of favourable economic processes the balance of payments deficit declined, as 
did public debt both in absolute value and in terms of GDP. The fact that a considerable part of capital investment was due to reinvesting income earned in Hungary, is a welcome tendency.

The Hungarian economy is now past the era of greenfield investment relying on tax incentives and cheap labour. In order to attract high quality investment a favourable economic climate needs to be created, with stable and reliable public finances and a well-qualified and healthy workforce being the most important decision criteria of investors. By making for better standards in health care the likelihood of attracting and channelling investment into the higher value-added services and manufacturing sectors may be significantly increased.

Higher value-added projects have superseded mere "assembly-type" operations as the main targets of new investment. In the recent past the Hungarian economy has been shaped by the investment and expansion projects of companies like Sanyo, Elcoteq, Nokia, Suzuki, SAP, IBM, Electrolux, Cisco, Bridgestone, Hankook, Michelin, Audi, Bosch, GE Money Bank, EDS and Renault-Nissan. The presence of this type of investors indicates that a number of investment projects requiring a great deal of intellectual input have been emerging, although the knowledge-based economy - and its intellectual breeding grounds: knowledge centres and research facilities of both universities and the Academy of Sciences - exists only in a rudimentary form. Multinational companies operating in the fields of biotechnology, computer hard- and software, road vehicles and microelectronics are increasingly facing the problem of bottlenecks in recruiting healthy and trained personnel, whom they can rely on on a permanent basis.

In 2005 foreign investors - for the first time since the outset of the transition to a market economy - withdrew more funds from Hungary than they reinvested. As evidenced by the balance of payments data published by the Central Bank - revised according to EU statistics guidelines and restated for the past 10 years -2005 was the first year in which the dividends paid out were in excess of income reinvested. In the light of the current trends it seems likely that foreign investors will continue to withdraw more funds than they plough back in the years to come, particularly if the signals inherent in the convergence programme are perceived as adversely affecting the investment climate. (Fig 1).

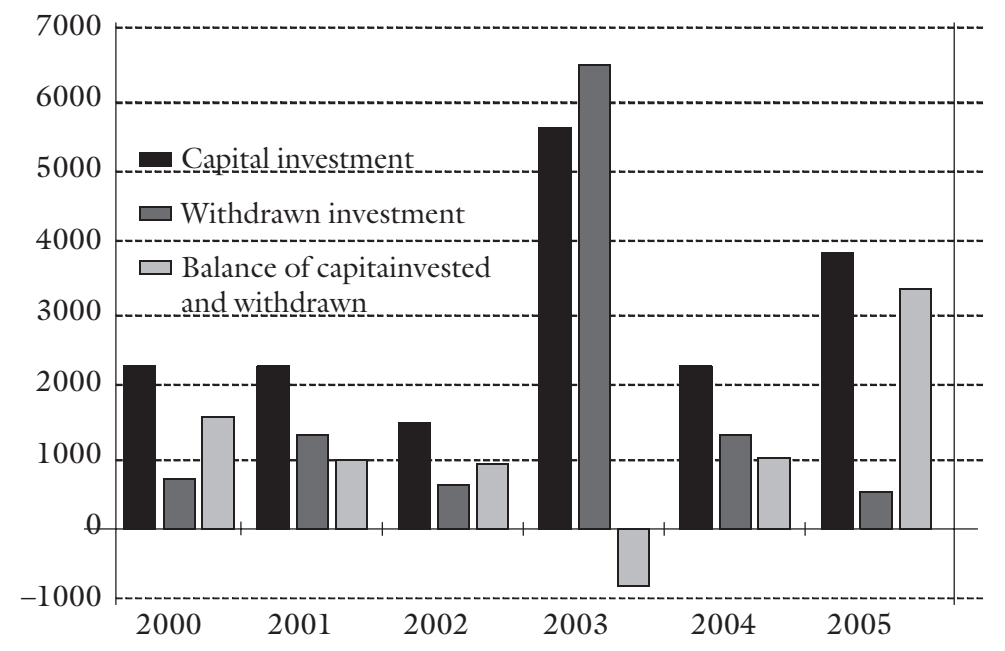

Fig. 1 Trends in foreign direct investment in Hungary (without the reinvested profits, in million Euros) (MNB, 2006) 


\section{New Perspectives and Dimensions in the European Financial Area}

In analysing the current position and outlining a vision for the future of public services in Hungary we must account for the convergence programme, i.e. the compliance procedure within the scope of which the country aims to align its budget deficit, public debt, inflation rate and exchange rate mechanism with the requirements of the European Monetary Union.

In order for the new member states to introduce the common currency they have to strive for fulfilling the Maastricht convergence criteria and they have to join ERM II, i.e. the common exchange rate mechanism. Upon being admitted to the European Union each country undertakes to join the Monetary Union and to introduce the Euro as its currency, once it has complied with the set of criteria for joining the common monetary system.

In 2005 the Hungarian government submitted to the EU its proposal aimed at reducing the budget deficit and public debt. The objective of slashing the budget deficit was deemed necessary by EU officials. However, the means by which this objective was to be achieved were said to be unsatisfactory and lacking sufficient detail. As a consequence, the European Union rejected the said proposal. The Hungarian government prepared a new draft and submitted the new convergence programme to the European Commission on September 26, 2006. This time the Commission approved of the submitted documents. The commitment of the fiscal authorities is beyond doubt as the convergence process is key to the future success of the Hungarian economy. Similar to other member states preparing to join the monetary union, the primary responsibility for working out and implementing the convergence programme rests with the government. The Central Bank is playing an important role in its implementation as well, predominantly in the domain of monetary and exchange-rate policies. The admission to ERM II and the introduction of the Euro are important milestones of the convergence process. These challenges facing the Hungarian economy can only be tackled successfully if there is agreement and cooperation between the government and the Central Bank.

The long-term predictability of budgetary processes and exchange-rate stability are not only Maastricht criteria but major cornerstones of fast and sustained economic growth. By joining the eurozone, where price stability has been achieved, the Hungarian economy shall be provided with the opportunity to more swiftly exploit the advantages stemming from stability and predictability and to thereby converge faster towards the economies of more developed EU member states. Of all ten new member states, however, Hungary is farthest away from introducing the Euro.

In reference to the compliance with the above-mentioned criteria it is important to note that the creation of a stable fiscal environment would be conducive to the competitiveness of the Hungarian economy, as fiscal stability is key to the sustained economic success of the country, also giving a lasting stimulus to the growth of the tertiary sector (health care and education among others). In the quest to return to a sustainable growth path it is of course more reasonable to adjust key fiscal parameters while the government is free to do so at its own discretion rather than wait until external lenders start demanding higher risk premia thereby enforcing measures deemed appropriate by the market.

Among the most important reasons for the derailment of fiscal policy are the pressure exerted and the demands placed upon public finances by the electorate and the society. The fiscal policies of recent years - lowering the tax burden and increasing government spending - have led to persistently high budget deficits. Compared to the figures set out in the convergence pro-

2007 - Volume 1, Number 1 
gramme the deficit target was missed by an amount equivalent to 2 percent of GDP in 2004 and to 3 percent of GDP in 2005 [7]. In the past three years tax revenue declined by an amount equivalent to 1.5 percent of GDP due to various tax cut schemes, while current primary government expenditures rose from 35 percent of GDP in 2000 to over 40 percent. The rise in fiscal deficit is thus fundamentally due to structural, social and political reasons. As a consequence, the delicate balance between revenues and expenditure was upset in Hungary in recent years. The methods applied thus far in remedying the situation, such as curbing investment spending or the outsourcing of infrastructure projects to publicly administered organisations and agencies operating outside the budget framework were at best superficial. Such fiscal doctoring, of course, leaves the flawed fundamentals unchanged and is thus futile in the long run.

The stabilisation of public finances, providing for a predictable economic environment, is one of the key ingredients in the effort to get the Hungarian economy back on track. It is obvious that there were neither a curtailment of spending, nor measures to increase tax revenue in the run-up to the 2006 general elections. It is of utmost importance that the measures aimed at reducing the budget deficit be introduced as soon as possible in the current term of Parliament from 2006 to 2010, but only after thorough circumspection and in a way not compromising the crucial factors of economic competitiveness. The compliance with the Maastricht criteria and, perhaps more importantly, securing the return of the Hungarian economy to a sustainable long-run growth path can only be achieved by such austere means.

Since the mid-1990s the Hungarian economy has boasted an unbroken growth record, save the short spell of economic slowdown following the year 2000. In 2005 the growth rate of GDP was 4.2 percent per annum. This statistic implies that Hungary has lost its growth edge over most of the new EU member states. Public finances are fraught with problems. Thus balancing fiscal revenues and expenditure is one of the most important tasks, indispensable for creating an environment conducive to long-term economic competitiveness. By joining the eurozone - a precondition of which is the stabilisation of public finances - Hungary will become even more deeply integrated into the European economy, with the integration exerting a favourable effect on the competitiveness of the economy.

According to the projection of the government's convergence programme, prepared in August 2006, the GDP growth of 4.1 percent forecast for the current year will slow to 2.2 percent, while the budget deficit will fall from 10.1 percent to 6.8 percent of GDP in 2007. At the same time, mention should be made of some important accompanying phenomena: the inflation rate is likely to almost double (from 3.5 percent to 6.2 percent), while public debt in terms of GDP is expected to rise from 67.9 to 71.5 percent $[1,2]$. Thus the overall competitive position of the Hungarian economy will be impaired as public debt and inflation, two of the most important economic indicators, are going to deteriorate. Economic slowdown and unfavourable trends in the inflation rate may have an adverse effect on the health care sector as well.

\section{Healthy Labour and a Sound Social Security System as New Competitive Factors}

In addition to a stable and predictable fiscal environment and to a modern and flexible vocational training scheme the competitive position of individual countries is largely affected by the health status of their workforce and the efficiency of their social security systems. The

HUNGARIAN MEDICAL JOURNAL 
Hungarian society saw the emergence of a new middle class over the past fifteen years or so. This middle class is relatively well-educated and has a sound financial position.

Simultaneously, society witnessed the formation of a class consisting of socially marginalised individuals and families, a caste much more populous than the aforementioned one. People in this social class tend to have inferior education, poorer housing and a worse health status, with their children having only a slim chance of breaking out of this sorry pattern. The persistent economic inactivity observed in this population group is likely to reproduce poverty. This social class is also characterised by territorial clustering, living mainly in the economically backward regions of Hungary. When accounting for those individuals relying on social welfare on a permanent basis, we observe that there is a fiftyfold difference between the small regions ${ }^{2}$ situated around Budapest on the one hand and those in the north-eastern part of the country on the other.

Ever since the economic transition process began, the private sector has been marked by a dichotomy. On the one hand there are the big multinationals priding themselves on spectacular growth and investment projects, and on the other small domestic businesses, poorly endowed with funds, struggling to survive. This dichotomy in the economy is creating a society divided in two: a middle class enjoying the benefits of stable and high income and a population group facing an ever worsening income situation and inferior conditions of living [8]. The latter class is placing overwhelming demands on the Hungarian social security system and social welfare scheme. As a consequence of the strained budget situation there are less and less funds available to cater for the needs of this impoverished population group. By integrating this class into the labour market the pool of workforce from which small and medium enterprises as well as multinationals could recruit personnel would be enlarged, there could be - in principle - more domestic start-ups and finally the dismal employment rate could be improved. By channelling these people towards the labour market the burden and demands placed on the social security system could be eased. The scores of poorly qualified people and the run-down infrastructure in economically backward regions such as Szabolcs-Szatmár-Bereg county and the districts stretching along the border in South-Western Hungary are scaring potential investors away.

It is safe to assert that the health status of not only the socially marginalised group of individuals but of the Hungarian society as a whole is considerably worse than would be justified by the prevailing socio-economic conditions. Every fifth citizen of Hungary is suffering from some kind of permanent illness or is disabled. On average, the female and male populations enjoy 57.8 and 53.5 years of good health, respectively, as opposed to 66 and 64.5 years in the European Union. The grim public health situation and the crisis-ridden health care system are undermining the competitiveness of the economy in the long-run.

Hungary has to cope with a low employment rate (56.1 percent in 2004), while a strikingly high proportion of the population ( 37.3 percent) is economically inactive, implying that a significant share of those with no employment are not even seeking a job. The other major problem placing a burden upon the social security system is the ageing of the population. About one third of the budget deficit is attributable to the deficit of the pension insurance fund. This is currently amounting to about 2 percent of GDP. According to forecasts this deficit is going to increase steadily in the future and may even double in thirty years time. Due to adverse demographic trends we will arrive at a situation in the year 2030 where there will be only two economically active individuals per retired person. The reason for this dramatic demographic situation is the ageing of the population. Movements in the old-age dependency ratio are closely tracking the ageing index (Fig. 2), as the former is increasing as well. This should be obvious as the old-age dependency-ratio-curve in the graph is plotting the ratio between the population 
older than 65 years and the economically active population. According to the old-age dependency ratio there were 21 dependants of over 65 years of age for every 100 working-age people in 2001 . By 2005 the same ratio rose by 1.7 persons (22.7 percent). Beyond 2010 we obtain a statistical forecast of the old-age dependency ratio that is progressing at a slower rate and more smoothly than the ageing index. A 1.36 percent rise is being forecast for the period between 2005 and 2010, with the ratio approaching 25.42 percent in 2050. In the year 2005 a workingage individual had to provide sustenance for 0.227 old-age dependants, with the same figure predicted to reach 0.2406 in 2010 [4].

The ageing index is the ratio of old-age individuals (over 65 years of age) to minors ( 0 to 14 years of age). This ratio will dramatically deteriorate to exceed 140 percent after 2030 as a consequence of adverse demographic trends. It is obvious then that Hungary is facing dim demographic prospects, and this tendency will generate further funding problems in the Hungarian social security system.

As a corollary of the low activity rate among the working-age population, the ageing issue and the introduction of a new pension system (partly relying on private sector pension funds) the solvency position of the publicly financed and publicly administered social security system is going to deteriorate. Younger generations with a better financial position are going to enter private pension schemes, while the task of providing for 3.1 million pensioners (including those relying on disability benefits) "staying" in the old scheme will place ever growing funding requirements on the budget as the deficits of the national pension insurance fund continue to increase. In 2001 the central government's budget provided 81.3 billion forints to the pension insurance fund to make up for contributions lost due to individuals switching to private pension funds and transferred another 51.8 billion forints in "liquid budgetary funds". By 2006 this "bailout" rose fourfold: 211.2 billion forints were directed towards making up for lost contributions and an additional 187.2 billion forints in "liquid budgetary funds" were transferred to the national pension insurance fund (Fig. 3).

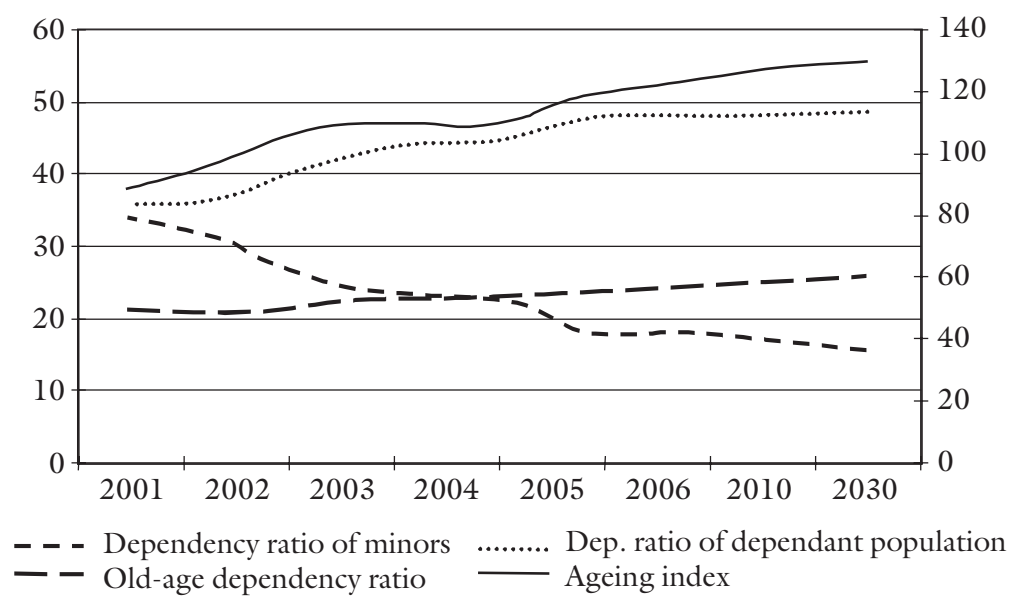

Fig. 2 The dependency ratio and the ageing index in Hungary, (2004, 2005, calculations of the author) The dependency ratio of minors and the old-age dependency ratio are referred to the left scale, the two other charts to the right scale

HUNGARIAN MEDICAL JOURNAL 
The issues of social clustering, an ageing society, and the public health situation are fundamentally intertwined. There is statistical evidence that people living in rural areas are more frequently seeing their physicians than their fellow citizens living in towns and cities. In 2005 $81,421.5$ medical examinations were performed per 1,000 inhabitants in villages. The same figure was 18 percent less in towns and cities in 2005. The number of medical treatments is rising with the frequency of people consulting their physicians. Nationwide figures on medical treatments are showing a 19.8 percent increase between 2001 and 2002, with year on year increases of 37.8 percent in 2003, 9.6 percent in 2004 and 10.8 percent in 2005. This increase in the number of people seeking medical advice is due to a better standard of living on the one hand and to the deteriorating health status of the population on the other. Another important factor behind the rising number of medical treatments is stemming from the funding peculiarities of the health insurance scheme: doctors tend to prescribe and perform more examinations than necessary, the effects of which are sometimes not unambiguously positive. The health care system was overhauled in 1995: due to changing rules and regulations a sharp increase in ambulatory care was observed. The number of medical treatments reached 204 million in 2004, while the hours worked by physicians amounted to 17 million. Over the four-year period from 2000 to 2004 the number of treatments increased by 30 percent, while the hours worked by doctors rose by 6 percent. The number of tests and analyses carried out in laboratories rose by 46 percent between 2000 and 2004.

Due to the idiosyncratic nature of the market for pharmaceuticals in Hungary there has been no significant change in resources allocated to the so-called pharmaceuticals fund (a subsystem of the health care system) over the past five years. Subsidies amounted to 80 billion forints in 2001 and about 90 billion forints in 2006. The larger part of the bill for pharmaceutical products and prescription drugs is footed by the sick themselves. While sick individuals paid 180 billion forints for pharma products in 2001, it is estimated that they spent approximately 320 billion forints on such products in 2006.

The negative tendencies in the economy are hitting those belonging to underprivileged social groups even harder. For example, the share of people relying on disability benefits relative to the total population is highest in economically backward regions (8.09 percent in Békés county, 7.97 percent in Szabolcs-Szatmár-Bereg county, 8.52 percent in Tolna county as opposed to 3.04 percent in Zala county, 3.25 percent in Fejér county and 3.33 percent in Vas county).

The fact of the matter is that the chances of integrating people living in backward peripheral regions and marginalised social classes into the labour market are growing increasingly slimmer. In addition to the above strains such population groups, already living in deprived conditions, are facing the prospect of the deterioration of their health status. As a straightforward consequence the burden placed on the social security system and thus the budget is growing to increase, while health care will be chronically short of funds. Ever since the fall of communism the expenditure of the health insurance fund has always been in excess of its revenues. From 2002 onward, when the budget started to get into trouble, a sharp increase in the deficit of the health insurance fund may be observed (Fig. 3). This is a further indication that the health-care potential is fundamentally determined by the situation surrounding public finances (and by budget constraints), and that the future prospects of health care in Hungary are closely intertwined with the prevailing fiscal conditions (Fig. 3).

It is obvious that the health care system is not capable of permanently improving the health status of the Hungarian workforce. This is being evidenced by continuously rising sick statistics and patient numbers. In Hungary expenditure on health care is 7.8 percent relative to GDP, 


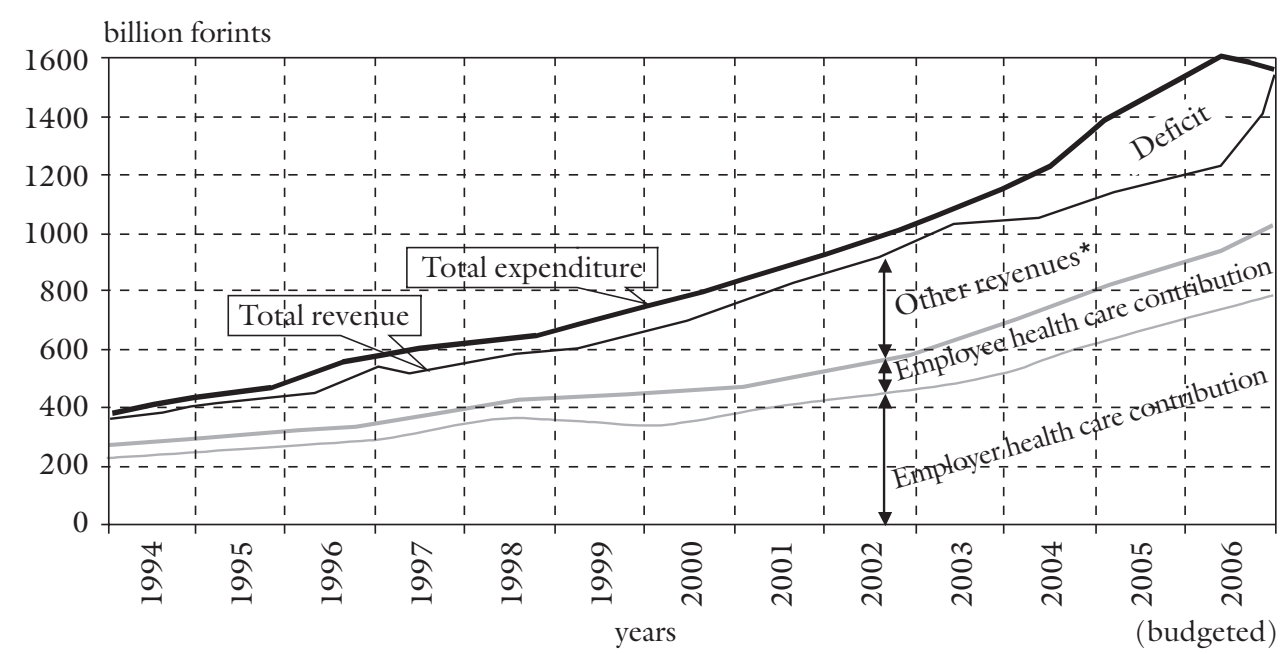

* e.g.: flat rate health care contribution, miscellaneous budget transfers

Fig. 3 Expenditure and revenues of the health insurance fund (EÜM, 2006)

somewhat less than the average of the $25 \mathrm{EU}$ member states ( 8.62 percent). It has to be added, however, that the labour market will not be able to provide to the economy the adequate number of healthy working-age people with the relevant knowledge - constituting an important competitive factor - unless the health care system is radically overhauled. The underfunded health care system simply cannot halt the rapid decline in the health status of the Hungarian population (and consequently cannot counter the worsening life expectancy situation).

\section{The Effects of the New Government's Manifesto and the Convergence Programme}

The manifesto of the new government entitled "Freedom and Solidarity" and the draft convergence programme first published in late August 2006 are setting out their action plan based on the fundamental insight that the past five years saw ever more and heavier burdens being placed on the budget. The justifiable cause of social and modernisation objectives was not coupled with due fiscal responsibility. Abandoning the path of sustainable development endangers both the economic and social stability of the country. The agenda of social justice and modernisation is being put in jeopardy by the unacceptably high sustained levels of the budget deficit and public debt. As the government is eager to fulfil the set of Maastricht criteria, its main objective is the quick and lasting reduction of the budget deficit. In relation to the target deficit of 6.1 percent of GDP in the 2006 budget it is now safe to say that without one-off immediate measures the annual deficit would reach 11.6 percent. The austerity measures already taken by the government - increases in taxes and social security contributions, the introduction of new taxes, measures aimed at establishing a lean government structure, the freezing of salaries in the public sector, reducing prescription drug subsidies, raising the price of natural gas paid by private individuals, etc. - would have the com-

HUNGARIAN MEDICAL JOURNAL 
bined effect of reducing the deficit by 4.5 percent per annum. Yet these measures, having been taken in the middle of the year and entering into force as of September 1 , will only affect the four month period until December. Thus - on a pro rata basis - the deficit reduction effect of the above measures is being estimated to amount to about 1 percent of GDP.

Budget expenditure will reach the equivalent of 51.7 percent of GDP in 2006. The government pledges to scale down this ratio to 45.3 percent by 2009 . As a consequence of the aforementioned measures the current operating expenditures of the budget stand a good chance of being reduced from 18.6 percent in 2005 to 15.2 percent in 2009 in GDP terms. In addition to the taxes newly introduced in the summer of 2006 (withholding tax on savings, tax on the (excessive) cash holdings of businesses ${ }^{3}$, minimum tax on wages and salaries) the government is going to introduce property $\operatorname{tax}^{4}$ as of 2008 . Furthermore the abolition of the local business tax, objected to by the European Union, is now being deemed infeasible by the government.

Further austerity measures are expected to affect social spending: for example individuals seeking to claim early retirement benefits are going to face tougher controls and prerequisites as of 2009. What is more, pension benefits shall be established based on gross wages and salaries from 2013 onward and they will be subject to income tax. The already poor health status of Hungarian citizens could be further deteriorated by the fact that only individuals paying their healthcare contributions and those for whom the state undertakes to pay such contributions will be entitled to comprehensive health care services. Over and above their contribution the sick will be liable to pay part of the medical bill arising from treatment. The measures envisaged in the health care sector are going to hamper efforts to integrate individuals of a humble social background and those without a job into the labour market. One of the most important competitive factors of the Hungarian economy is thus critically affected by the measures taken under the convergence programme.

The intention to curtail spending is a clear-cut priority of both the new government's economic and social agenda and the convergence programme. The fact that the spending cuts will primarily affect health care and vocational education, two of the most important areas in the reproduction of the workforce, is giving rise to serious concerns. It is a well-established fact that current trends in public finances are adversely affecting the inflation rate and public debt levels, as well as undermining the growth prospects. Once accounting for their combined effect it is easy to see how the situation is aggravated by these factors amplifying each other and leading to a downward spiral. However, no impact studies were carried out to examine how the policies aimed at stabilising the budget will work out in the long run. In the light of the above account the Hungarian economy should brace itself for a decline in its competitive position, for widening gaps between social classes and for a deterioration in the conditions of living.

It is safe to say that the cancellation of funds and constant budgetary restraints are not serving the cause of economic competitiveness and are not improving the efficiency of the competitive factors underlying a sound economy. As for the health care sector Hungary better prepares itself for an increased set of tasks as a consequence of growing unemployment and the deteriorating health status of the population. This will force decision makers to provide the sector with additional funds according to the respective funding requirements, without having worked out the details of a comprehensive strategy underlying the overhaul of the system. Delaying reforms will mean that the health care sector is going to remain a traditional tertiary sector financed by public funds, instead of becoming a sector that, as a vital component to economic success, is creating value and improving the health status of the population. 


\section{Notes}

1 This is the balance of capital invested and withdrawn.

2 Smallest territorial entity recognised by the European Union, used in devising regional development strategies.

3 The tax on the (excessive) cash holdings of businesses was annuled in November 2006 by the Constitutional Court of Hungary.

${ }^{4}$ Similar to the British Council Tax except that it is not being levied by local councils but the central government.

\section{References}

[1] The Manifesto of the Government of the Republic of Hungary, 2006 (For a Successful, Modern and Equitable Hungary - 2006-2010); Office of the Prime Minister, Budapest.

[2] The Convergence Programmes of the Republic of Hungary. 2005, 2006, Office of the Prime Minister, Budapest.

[3] Demographic Yearbook 2004, Bureau of Statistics, 2005, Budapest.

[4] Health Statistics Yearbook, 2004, 2005, Bureau of Statistics 2005, Budapest.

[5] The Old-Age Population in Hungary, 2004, Bureau of Statistics 2005, Budapest.

[6] Health and the Quality of Life 2004, Bureau of Statistics 2005, Budapest.

[7] Report on the Convergence Processes, Central Bank of Hungary, 2005.

[8] Csaba Lentner, 2005, Regime Change and Fiscal Policies, Akadémiai Kiadó. 